\title{
A Study on Standard of Buffalo Meat Hygiene in Dharan
}

\section{BHASKAR MANI ADHIKARI ${ }^{1,2 *}$, RAJENDRA PRASAD SUBEDI ${ }^{1}$ and DILIP SUBBA ${ }^{1}$}

\author{
${ }^{1}$ Central Campus of Technology, Hattisar, Dharan, Nepal \\ ${ }^{2}$ National College of Food Science and Technology, Khusibu, Kathmandu, Nepal
}

\begin{abstract}
Hygiene standard of buffalo meat in Dharan was assessed by microbiological analyses and field survey method. Ten samples of buffalo meat, knives, chopping board and hands of butchers were examined for total plate count (TPC), total coliforms, E. coli, Staphylococcus aureus, Salmonella and Shigella. Average of TPC, Coliforms, E. coli and S. aureus counts in meat were $3.59 \times 10^{7}$, $2.06 \times 10^{4}, 1.69 \times 10^{3}$ and $9.67 \times 10^{3} \mathrm{cfu} / \mathrm{g}$ respectively. Salmonella was detected in $80 \%$ samples and all samples were Shigella positive. The average TPC count of chopping board, knives and hands were found to be $3.15 \times 10^{4}, 3.47 \times 10^{3}$ and $2.01 \times 10^{4} \mathrm{cfu}$ / $\mathrm{cm}^{2}$ respectively. The average Coliform, E. coli and S. aureus counts of chopping board were found to be $1.11 \times 10^{3}, 9.8 \times 10^{1}$ and $6.2 \times 10^{2} \mathrm{cfu} / \mathrm{cm}^{2}$. The average Coliform, E. coli and S. aureus counts of knives were found to be $1.31 \times 10^{3}, 1.66 \times 10^{2}$ and $2.83 \times 10^{2}$ cfu/cm ${ }^{2}$. The average Coliform, E. coli and S. aureus counts of the palms of butchers were found to be $1.95 \times 10^{3}, 1.66 \times 10^{2}$ and $1.77 \times 10^{2} \mathrm{cfu} / \mathrm{cm}^{2}$. Two chopping boards, three knives and three hands were found Salmonella free. Five chopping boards, three knives and two hands were detected for Shigella. The field survey of 31 meat shops showed that the hygiene condition of meat sold in Dharan was found unsatisfactory.
\end{abstract}

Keywords: Buffalo meat, Hygiene, TPC, Coliforms, S. aureus, Salmonella, Shigella

\section{Introduction}

The nature and level of microbial contamination in meat have important consequence in relation to public health, storage life and the type of spoilage of meat (Gracey and Collins, 1994). The microbiology of carcass meat is highly dependent on the conditions under which animals are reared, slaughtered and processed. The extent to which contamination occurs and the composition of the flora reflect the standard of hygiene (Brown, 1982). The most important pathogens associated with meat include Salmonella, Staphylococcus aureus, Escherichia coli, Clostridium perfringens, Campylobacter jejuni, Listeria monocytogenes, Yersinia enterocolitica and Aeromonas hydrophila (Koutsoumanis and Sofos, 2004).

The prevalence and levels of bacteria on meat carcasses depend on a number of factors including the origin of the animal, sanitation procedures and hygienic practices employed during handling and processing and conditions of storage. Extremely high numbers of microorganisms are found in the animal's intestinal content, and it is expected that some will find their way to the surface of the carcass during the dressing operations. Micro organisms reach the carcass via butcher's hands, tools, clothing, water etc. The number can be proliferated during cutting and distribution (Wilson et al., 1981; Khedkar et al., 2003). Raw meat quality is often judged by the size of its microbial population able to grow at $30-37^{\circ} \mathrm{C}$. However, this count is most appropriately used to monitor hygiene (Brown and Baird-Parker, 1982).

Dharan Municipality (2112 hectare area), located in the eastern Terai of Nepal stretches from the edge of the northern Mahabharat hill range up to the Charkoshejhadi in the south, which separates it from the southern Terai. The per caput meat consumption is $13 \mathrm{~kg}$ compared to national $9 \mathrm{~kg}$ per caput

\footnotetext{
*Corresponding author, E-mail: vaskarmani@gmail.com
}

consumption. This shows high meat consumption by the people living in Dharan. This study was conducted out in 2005 to study the general condition of meat market and standard of hygiene of meat marketed in Dharan. Dharan had then the population of one hundred fifty thousands. Chickens used to be slaughtered at 179 places, pigs at 64 , buffaloes at 10 , and goats at 11 places. Buffalo meat shops (31) were spread all over the town.

\section{Materials and Methods}

Duplicate destructive samples of buffalo meat having sample size of $250 \mathrm{~g}$ from randomly chosen 10 places (out of 31 shops) were collected in the morning time of at 6-7 AM in sterile polythene bags without contacting by the collector and analyzed within $2 \mathrm{hrs}$ of collection. Sample was processed immediately as soon as possible. An ice box was used during the collection to discourage the growth of microorganisms. 25 gram of meat sample was aseptically transferred into meat mincer (National meat grinder, Model-MK-G10N, Matsusiuta Electric Ind. Company Ltd.) and $225 \mathrm{ml}$ sterile distilled water was also added in the same machine and homogeneous mixture of sample was obtained. Before starting the mincer, it was thoroughly washed with clean water, distilled water and finally sterilization with $70 \%$ alcohol. Samples were serially diluted upto $10^{-7}$ dilution according to KC and Rai, (2000). Samples from hands of butcher, chopping block and knife were collected from 10 shops out of 31 meat shops. As per Harrigan and McCane, (1979) Cotton wool swabs of $4 \mathrm{~cm}$ length and $1.5 \mathrm{~cm}$ thickness were used and distilled water was used as diluent. Total plate count was determined by pour plate method according to Harrigan and McCane (1979) using plate count agar and distilled water as diluent. Coliform and $E$. coli count was determined by pour plate method according to Varadaraj (1993). Staphylococcus aureus enumeration was carried out according to Brown (1982) and Varadraj (1993). 
Coagulase test was done for confirmation. Salmonella was detected according to the Varadaraj (1993) and Maaßen and stolle (2005) with some modifications as 20 gram grinded meat sample was placed in $80 \mathrm{ml}$ sterile peptone water for pre enrichment and incubated at $37^{\circ} \mathrm{C}$ for $16-20 \mathrm{hrs}$ followed by enrichment in Selenite F broth for $24 \mathrm{hr}$ at $37^{\circ} \mathrm{C}$. Then serial dilution was carried in distilled water. Further which was cultured on Bismuth Sulphite Agar at $37^{\circ} \mathrm{C}$ for $24 \mathrm{hr}$. Biochemical testing of colonies in Triple-sugar Iron Agar was done. Shigella was detected according to Harrigan and McCane (1979). A questionnaire was prepared to evaluate sanitary condition of meat shops and personal hygiene of butcher.

\section{Results and Discussion}

Microbiological quality of meat- The count obtained from meat samples, swabs of knives, swabs of cutting board and hands of butchers taken from ten different locations for the parameters total plate count (TPC), total coliform (TC), E. coli, Staphylococcus aureus are represented in Figure 1.

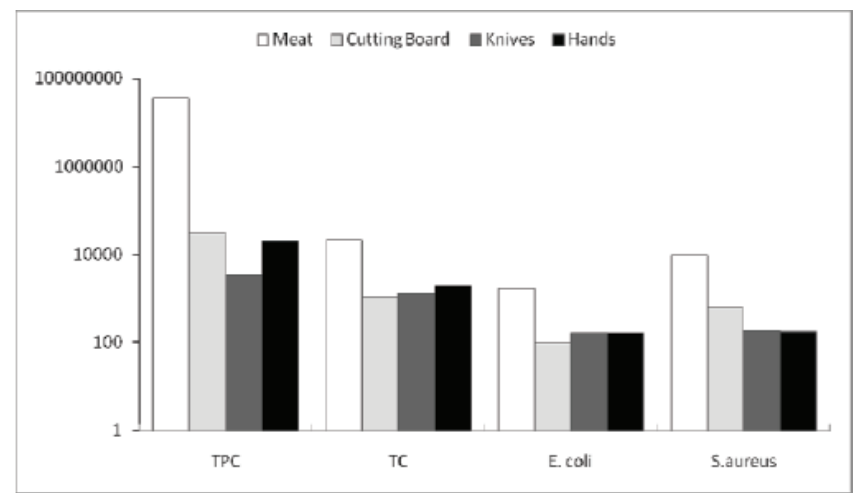

Figure 1. Microbial counts of buffalo meat, knives, cutting board and hands of butcher

Figure 1, shows the count for TPC of 10 samples. Average value for meat samples was found to be $3.59 \times 10^{7} \mathrm{cfu} / \mathrm{g}$ with the maximum $9.6 \times 10^{7} \mathrm{cfu} / \mathrm{g}$ and minimum as $2.2 \times 10^{6} \mathrm{cfu} / \mathrm{g}$. The coliform, E. coli and Staphylococcus aureus counts were $2.06 \times 10^{4}, 1.69 \times 10^{3}$ and $9.67 \times 10^{3} \mathrm{cfu} / \mathrm{g}$, respectively. The count

Table 1. Detection of Salmonella and Shigella in Buffalo Meat, Chopping board, knives and hands of butchers

\begin{tabular}{|c|c|c|c|c|c|c|c|c|}
\hline \multirow[t]{2}{*}{ Source } & \multicolumn{4}{|c|}{ Salmonella } & \multicolumn{4}{|c|}{ Shigella } \\
\hline & Meat & Board & Knives & Hands & Meat & Board & Knives & Hands \\
\hline $\bar{A}$ & + & + & - & + & + & + & - & + \\
\hline B & + & - & + & - & + & + & - & - \\
\hline $\mathrm{C}$ & - & - & - & - & + & - & - & - \\
\hline D & + & - & - & - & + & + & + & - \\
\hline $\mathrm{E}$ & + & - & - & + & + & - & - & - \\
\hline $\mathrm{F}$ & + & - & - & - & + & - & - & - \\
\hline G & + & + & + & - & + & + & + & - \\
\hline $\mathrm{H}$ & + & - & - & + & + & + & - & - \\
\hline I & - & - & + & - & + & - & - & - \\
\hline $\mathrm{J}$ & + & - & - & + & + & - & - & $+{ }^{`}$ \\
\hline
\end{tabular}

for TPC of chopping board, knives and hands of butchers were found to be $3.15 \times 10^{4}, 3.47 \times 10^{3}$ and $2.01 \times 10^{4} \mathrm{cfu} / \mathrm{cm}^{2}$ respectively. The coliform, E. coli and staphylococcus aureus counts of chopping board were found to be $1.11 \times 10^{3}, 9.8 \times$ $10^{1}$ and $6.2 \times 10^{2} \mathrm{cfu} / \mathrm{cm}^{2}$, respectively. The coliform, E. coli and staphylococcus aureus counts of chopping knives were found to be $1.31 \times 10^{3}, 1.66 \times 10^{2}$ and $2.83 \times 10^{2} \mathrm{cfu} / \mathrm{cm}^{2}$. The coliform, E. coli and Staphylococcus aureus counts of the palms of butchers were found to be $1.95 \times 10^{3}, 1.66 \times 10^{2}$ and $1.77 \times 10^{2} \mathrm{cfu} / \mathrm{cm}^{2}$.

Altogether $80 \%$ meat samples were found to be salmonella positive, whereas shigella was detected in all samples. In case of Salmonella two samples of chopping board, three samples of Knives and three swab samples of hands of butchers were found to be positive. Out of ten swab samples, five samples of chopping board, three samples of knives and two samples of hands were found positive for Shigella.

The data showed higher number of microbes on meat samples which might be due to other contaminating sources also. The cross contamination from these sources could not be ignored. Selling of intestinal and respiratory tract along with the meat and handling by same man with same cutting knives can spread the Coliforms and other microbes. The prevalence of Salmonella and Shigella in knives, chopping blocks and hands signify that they are the main vector for its distribution.

Microbiological analysis showed heavy contamination of knives, chopping blocks and hands. Because of varied sources, the kinds of microorganisms likely to contaminate meat are many. This directly reflects highly polluted and unhygienic 
condition of meat being sold in local market of Dharan. High numbers of Coliforms on these contaminating sources indicate inadequate cleaning, unsanitary handling and post processing contamination from dirty atmosphere around shops. Fecal Coliform group is of hygienic implication. Because of involvement of $E$. coli in several cases of food poisoning, it indicates presence of other pathogenic flora. As an indicator of hygiene and sanitary condition, $E$ coli count suggests consumers are at greater risk of being food poisoned. So, tools used for preparing meat can be said to be highly unhygienic and can be claimed as main spreader of these organisms. During the slaughtering operation, the equipment used comes in contact with maximum of animal surfaces. When the animal is cut and served to consumer equipments such as knives, cutting blocks and the seller's hand are the main sources for the cross contamination of the meat. The microflora thus gets transferred to cut meat surfaces by the knives.

Buffalo meat of local market can be said to be heavily contaminated with spoilage and pathogenic organisms, keeping in mind the unhygienic slaughtering conditions and lack of microbiological standards regarding meat in Nepal. This was previously found by a study also. The study of Munankami (1998) has revealed counts of $1.3 \times 10^{5}$ and $5.6 \times 10^{4}$ $\mathrm{cfu} / \mathrm{g}$ total Coliform and pathogenic Staphylococci count in the buffalo meat purchased from the local market of Dharan. Salmonella was also reported to be present in the meat.

Taking the reference of microbial standards of Europe and United States, the average value for TPC was found to be higher than the inspected German quality meat standards referred for cutting and packaging plant which is less than $5.0 \times$ $10^{6} / \mathrm{g}$. It was also greater than the Oregon state microbiological standard for fresh meat i.e. $5 \times 10^{6} / \mathrm{g}$. The total Coliform count of the analyzed sample was also found greater than the EU microbiological standard of cut meat for retail sale and further processing i.e. $5 \times 10^{3} / \mathrm{g}$. The $E$. coli count was also found to be higher than the Oregon state microbiological standards of maximum 50/g. The average Staphylococcus aureus count of the samples collected from the market was found higher than the maximum limit of $5 \times 10^{3} / \mathrm{g}$ of EU microbiological standards of cut meat for retail sale and further processing. EU standards for meat require Salmonella negative in $25 \mathrm{gm}$ (Anonymous, 2003; Koutsoumanis and Sofos, 2004), but Salmonella was detected in most of the samples.

Sanitary condition of Buffalo meat shops of Dharan- It was found during the field survey that all meat sellers control the flies manually. $16.13 \%$ of the butchers clean their shops 2-4 times only in a week. Further $74.12 \%$ of the shops used water for cleaning, $22.58 \%$ used soap or detergent powder as sanitizing agent. Few (3.22\%) used cloth for the cleaning purpose. $90.32 \%$ butchers did not use apron while cutting and selling meat. All butchers of Dharan cleaned chopping block by scrapping with knife. 26 butchers cleaned their knives before use while $16.13 \%$ denied any cleaning of knives before processing. From the survey, $16.13 \%$ of the shopl :'s atmosphere was found dirty. Total $77.42 \%$ of the shops did not have any fencing to protect the meat from dogs and rodents. Only $9.67 \%$ sold meat on cemented platform. $45.16 \%$ sold meat on the wooden table while $32.26 \%$ used plastic sheet and $12.9 \%$ used metal sheet for serving meat in the shop.

When asked about leftovers, 29.03\% shops pretended to keep the meat in refrigerator but $93.55 \%$ shops did not use refrigerator while $35.49 \%$ sold the meat selling the following day. $29.03 \%$ served leftover meat as it is and only $6.45 \%$ said they dump the leftovers.

It was observed that no ante-mortem inspection of animals and postmortem inspection of carcasss meat and viscera were carried out. $64.52 \%$ of the butchers were unaware of zoonoses. Altogether, $70.97 \%$ denied having any idea of the Meat Act. Similarly, $48.39 \%$ of the butchers felt the necessity of slaughterhouse. When the butchers were asked about their knowledge about meat borne diseases and meat rules, 12.9 $\%$ denied having any idea about zoonoses, and 20 out of 31 butchers replied that meat was not a source of diseases for the human. 22 out of 31 informed that they were not familiar with the meat acts and rules.

Rickshaw (41.94\%) was found to be most prominent transportation vehicle. Only $9.67 \%$ used hand board for transporting meat from slaughter site. $25.81 \%$ used fourwheeler for the purpose and $22.58 \%$ carried meat themselves. $67.74 \%$ shops do not possess toilet facility nearby their shops. All butchers utilized previously reserved water for washing of meat.

Altogether, $32.26 \%$ of butchers sold animal hide on slaughtering site while $6.45 \%$ butchers sold the hide alongside with meat and $3.22 \%$ sold the meat without de-hiding. Feet of the slaughtered animal were found alongside with the meat of the $32.26 \%$ shops while $29.03 \%$ sold them away from shop. In $19.35 \%$ of the shops viscera was placed on table along with the meat, while $51.61 \%$ butchers dealt with the viscera away from the meat shop. Among them, $45.16 \%$ were found using same knife for the meat and viscera.

From the survey it was found that the hygiene in the vicinity of meat shop was quite unsatisfactory. The butchers and sellers seemed to be ignorant about the basics of slaughter hygiene and good manufacturing practice. 18 shops informed that they did not handle hide of slaughtered animal and there were 14 shops which procured prepared carcass from other butchers. There is high chance of contamination of meat with feet of slaughtered animal. $32.26 \%$ meat sellers sold the feet placing them together with meat, while feet were found separately placed in $29.03 \%$ of the meat shops. $51.61 \%$ sold the viscera farther away from shop. The access of houseflies 
to meat was apparent in all shops as the meats were sold in open environment.

Lack of cleanliness of the utensils, knives, etc. was among the reasons for the poor hygienic quality of the meat marketed in Dharan. The butchers were unaware of zoonoses and meat act. Practice of antemortem and postmortem inspection was totally lacking. These survey findings are comparable with the study results of Joshi and Olesen (1999). They reported that the majority of butchers (64.9\%) of Nepal lack awareness about meat borne disease, meat transportation was done by rickshaw, and only $14.29 \%$ of the meat shops had refrigeration facility.

\section{Conclusion}

All the buffalo meat samples were found to contain higher microbial load than prescribed standards of Europe and United States. The bacterial counts of meat samples were found to be high which might be due to poor sanitary condition of meat shop, handlers and slaughtering premises. Presence of E. coli indicated that the meat might be contaminated by the visceral content. Except two meat samples all were found to contain Salmonella Thus the study showed that degree of contamination is dependent upon the hygienic condition of those localities and the way of handling, cutting and preparing meat. All the findings of survey suggest about the unhygienic and unscientific method of handling, lack of sanitation and knowledge of micro organisms resulting higher number of contamination. The sanitary condition need to be improved. The government must develop microbiological standards of fresh meat and urgently put them in practice. The meat act must be implemented effectively. The control agency must be vigilant. Awareness programs for butchers and meat sellers also must be launched.

\section{References}

Anonymous, (2003). Manual Meat Production and Processing, $2^{\text {nd }}$ edition, TLDP, Department of Livestock services, Ministry of Agriculture and Co-operatives, HMG, Kathmandu, Nepal

Brown M. H. (1982). Meat Microbiology, Applied Science Publishers LTD, England.

Brown M. H. and Baird Parker A. C. (1982). The Microbiological Examination of Meat. In: Meat Microbiology. Brown, MH (eds) Applied Science Publishers LTD, England.
Gracey J. F. and Collins D. S. (1994). Meat Hygiene, $9^{\text {th }}$ edition, Balliere Tindall, London.

Harrigan W. F. and McCane M. (1979). Laboratory Methods in Food and Dairy Microbiology, Academic Press, London, New York.

Joshi D. D. and Olesen Hans K. R. (1999). Animal Slaughtering and Meat Marketing Practices in Nepal, National Zoonesis and Food Hygiene Consulting Center Pvt. Ltd., Tahachal, Kathmandu.

KC J. B. and Rai B. K. (2000). Experiments in Basic Food Microbiology R. C. Timotty for Ekta Books and Publishers, Kathmandu.

Khedkar C. D., Khedkar G. D., Gyanath G. and Kalyankar S. D. (2003). Buffalo Meat. In: Encyclopedia of Food Sci. and Nutri., $2^{\text {nd }}$ edition, Academic Press, Oxford, pp. 699-705.

Koutsoumanis K. and Sofos J. N. (2004). Microbial contamination. In: Encyclopedia of Meat Sci., Academic Press, pp. 727-737.

Maaßen C. and Stolle A. (2005). Salmonella- Still a problem. In: Fleischwirtschaft International, 2.

Munankami R. (1998). Microbiological and Physicochemical Quality of Dry Fermented Pork and Buffalo Sausages prepared at Ambient Temperature. B. Tech (Food) Dissertation, Central Campus of Technology, Dharan, Nepal.

Varadaraj M. C. (1993). Methods for Detection and Enumeration of Food-borne Bacterial Pathogens. $J$. Food Sci. and Tech., 30(1):1.

Wilson N. R. P, Dyett E. J., Hughes R. B. and Jones C. R. V. (1981). Meat and Meat products: Factors affecting quality control, Applied Science Publishers, London and New Jersey. 